International Journal of Current Advanced Research

ISSN: O: 2319-6475, ISSN: P: 2319 - 6505, Impact Factor: SJIF: 5.995

Available Online at www.journalijcar.org

Volume 6; Issue 5; May 2017; Page No. 3842-3847

DOI: http://dx.doi.org/10.24327/ijcar.2017.3847.0379

\title{
AT\&C LOSS REDUCTION IN ELECTRICAL DISTRIBUTION SYSTEM BY IMPLEMENTATION OF HVDS
}

\author{
Kirankumar P. Shinde ${ }^{1}$ and S. R. Deore ${ }^{2}$
}

1,2Department of Electrical Engineering, A.C.Patil College of Engineering, Kharghar, Navi Mumbai - 410210

\section{A R T I C L E I N F O}

\section{Article History:}

Received $20^{\text {th }}$ February, 2017

Received in revised form $12^{\text {th }}$ March, 2017

Accepted $11^{\text {th }}$ April, 2017

Published online $28^{\text {th }}$ May, 2017

\section{Key words:}

AT\&C - Aggregate Technical and Commercial, DTC-Distribution Transformer Centre, HVDS-High Voltage Distribution System, AGR-Agriculture, LVDS-Low Voltage Distribution System, DTRs-Distribution Transformers.

\begin{abstract}
A B S T R A C T
Some percentage of units is lost in Primary and Secondary transmission and distribution network. High percentage of losses comes under secondary distribution i.e. at $440 \mathrm{~V}$ and 220 V. In India the Transmission and Distribution (T\&D) losses have been consistently on higher side and reached to the level around 30\% which is higher compared to the accepted International norms. As the T\&D loss was not able to capture all the losses in the network, concept of Aggregate Technical and Commercial (AT\&C) loss was introduced. High technical losses in the system are primarily due to inadequate investments over the years for system improvement works, which has resulted in unplanned extensions of the distribution lines, overloading of the system elements like transformers and conductors. The commercial losses are mainly due to theft $\&$ pilferages. The improvements of power system performance to bridge the gap between demands and supply and the minimization of cost of energy have assumed higher importance for the power utilities of developing countries hence the reduction of losses has significant impact on the revenue.

We can improve the system by converting Low Tension (LT) distribution network into High Tension (HT) distribution network. Converting LT lines to higher voltage consist high initial cost but after some specified time period this system is beneficial. In agricultural sector, if we go for High Voltage Distribution System (HVDS) system it connects cluster of 2 to 3 Agriculture (AGR) customers employed a small distribution transformer of capacity $7.5 \mathrm{KVA}, 10 \mathrm{KVA}, 15 \mathrm{KVA}, 20 \mathrm{KVA}, 25 \mathrm{KVA}$ and $30 \mathrm{KVA}$ through almost negligible LT distribution lines. In HVDS there are less distribution losses due to minimum length of distribution line, high quality of power supply with no voltage drop. Installation of additional distribution transformers of low capacity at each consumer's premises instead of cluster formation will decrease the losses.
\end{abstract}

Copyright $(2017$ Kirankumar P. Shinde and $\boldsymbol{S}$. $\boldsymbol{R}$. Deore. This is an open access article distributed under the Creative Commons Attribution License, which permits unrestricted use, distribution, and reproduction in any medium, provided the original work is properly cited.

\section{INTRODUCTION}

The losses prevailing in the existing power distribution system can be classified as: a) Technical losses b) NonTechnical losses. Technical losses on distribution system are primarily due to heat dissipation resulting from current passing through conductors and magnetic losses in transformers. Technical losses occur during transmission and distribution involves substation, transformer, and line related losses. These include resistive losses of the primary feeders, the distribution transformer losses (resistive loses in windings and the core losses), resistive losses in secondary network, resistive losses in service line and losses in KWh meter. These losses are inherent to the distribution of electricity and cannot be eliminated but can be reduced. Non-Technical losses include tampering with the meter to create false

*Corresponding author: Kirankumar P. Shinde

Department of Electrical Engineering, A.C.Patil College of Engineering, Kharghar, Navi Mumbai - 410210 consumption information used in billings, making unauthorized connections to the power grid. Non-payment, as the name implies, refers to cases where customers refuse or are unable to pay for their electricity consumption. It is estimated that electricity theft costs in India is in crores in a year. Non-Technical losses (NTL) include electricity theft. Electricity theft is defined as a conscience attempt by a person to reduce or eliminate the amount of money he will owe the utility for electric energy. It is estimated that electricity theft costs in our country is in crores in a year. Both the technical and non-technical losses are together termed as AT\&C losses. In India, average AT\&C losses are estimated as $23 \%$ of the electricity generated. But in actual practice these losses are as high as $50 \%$ in some states of India. And thus it is necessary to focus on both side i.e. on technical losses as well as on non-technical losses and it can be achieved by using proposed HVDS method for distribution. The main advantage of using high voltage for distribution is to reduce the theft of energy and decrease in unauthorized connection as the LT lines are 
virtually eliminated and even short LT lines required will be with insulated cables i.e. ABC.

\section{STATE OF ART}

\section{Existing Low Voltage Distribution System (LVDS)}

In this paper we have applied the conversion of LVDS into HVDS of tapping of $11 \mathrm{KV}$ AGR feeder emerging from 33/11 KV Substation. The tapping of $11 \mathrm{KV}$ AGR feeder consists of 8 No's. of high capacity distribution transformers.

The single line diagram (SLD) of this tapping of $11 \mathrm{KV}$ AGR feeder is shown in Fig1

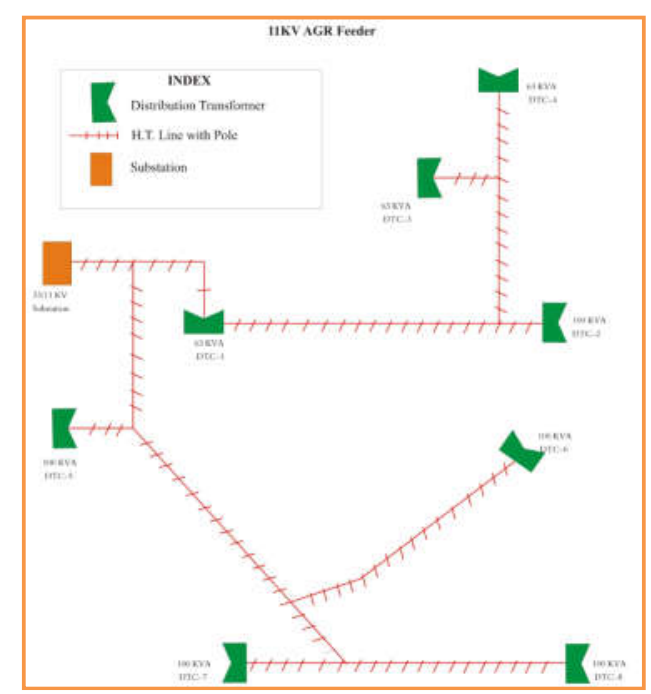

Fig 1 Single line diagram of tapping of $11 \mathrm{KV}$ AGR feeder

First walk down survey of consumers and connected load on DTCs has been carried out. For convenience purpose only one DTC i.e. DTC-7 is considered in the paper.

The single line diagram of existing LT network of DTC-7 is shown in below Fig 2. In this distribution transformer circuit is very lengthy $\&$ in only one direction. The $\% \mathrm{VR}$ is very poor at the end of circuit. Here we can see the maximum load of transformer is on only one circuit also the circuit length is high. If this distribution transformer is shifted at load center and making multiple circuits then we can reduce the technical losses. The complaints of poor voltage at the end of circuit can also be reduced by shifting the distribution transformer at load center.

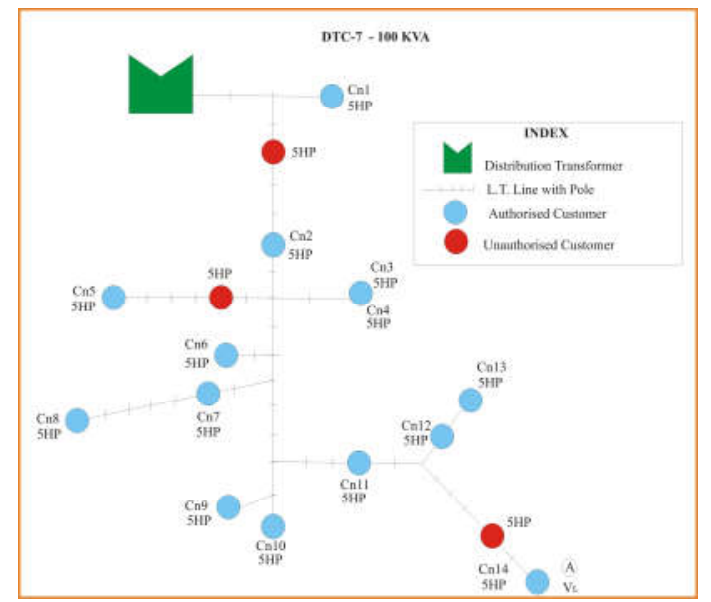

Fig 2 Single line diagram of LT network at DTC-7
The consumer wise details are given in Table I. It is showing total No's of connected consumers, their load and identity number.

Table I Consumer wise Details of DTC-7

\begin{tabular}{ccc}
\hline \multicolumn{3}{c}{ DTC-7 - 100 KVA } \\
\hline SR. NO. & $\begin{array}{c}\text { CONSUMER } \\
\text { IDENTITY }\end{array}$ & LOAD \\
\hline 1 & Cn1 & $5 \mathrm{HP}$ \\
2 & $\mathrm{HOOK}$ & $5 \mathrm{HP}$ \\
3 & $\mathrm{Cn} 2$ & $5 \mathrm{HP}$ \\
4 & $\mathrm{Cn} 3$ & $5 \mathrm{HP}$ \\
5 & $\mathrm{Cn} 4$ & $5 \mathrm{HP}$ \\
6 & $\mathrm{HOOK}$ & $5 \mathrm{HP}$ \\
7 & $\mathrm{Cn} 5$ & $5 \mathrm{HP}$ \\
8 & $\mathrm{Cn} 6$ & $5 \mathrm{HP}$ \\
9 & $\mathrm{Cn} 7$ & $5 \mathrm{HP}$ \\
10 & $\mathrm{Cn} 8$ & $5 \mathrm{HP}$ \\
11 & $\mathrm{Cn} 9$ & $5 \mathrm{HP}$ \\
12 & $\mathrm{Cn} 10$ & $5 \mathrm{HP}$ \\
13 & $\mathrm{Cn} 11$ & $5 \mathrm{HP}$ \\
14 & $\mathrm{Cn} 12$ & $5 \mathrm{HP}$ \\
15 & $\mathrm{Cn} 13$ & $5 \mathrm{HP}$ \\
16 & $\mathrm{HOOK}$ & $5 \mathrm{HP}$ \\
17 & $\mathrm{Cn} 14$ & $5 \mathrm{HP}$ \\
\hline
\end{tabular}

\section{Drawbacks of LVDS}

- Higher losses, poor tail end voltages, more fluctuations in voltage and frequent cuts fuse blowouts and motor burns out almost twice in each cropping period of 100 days.

- Due to frequent faults, more failures in distribution transformer and its maintenance and repair requires high expenditure. Due to delay in replacement of failed distribution transformers, there is a great loss in standing crops.

- Unauthorized hooking or tapping the bare conductors of low tension feeder or tampered service lines and monitoring of low voltage feeders is really very difficult.

- In case of any failure in three-phase large capacity distribution transformer, entire unit is to be replaced which consumes more time.

- High quantum of $\mathrm{I}^{2} \mathrm{R}$ losses.

- DTR failures due to frequent faults.

- High Rating Distribution Transformers are required to supply the Power to the consumers.

- As low Voltages are transmitting to large distances, the voltage profile at the load ends is decreasing.

- More resistive loss is present because of low voltage profile.

- Improper load management results in overloading of conductors and transformers.

- Monitoring of unauthorized hooking or tapping the bare conductors is of LT lines is more difficult.

- Nobody owns the transformer since everybody thinks that others will take care of the transformer.

\section{Analysis of Reasons of High Losses in LVDS}

The loss which occurs in distribution network is given by $\mathrm{P}=$ $3 \times \mathrm{I}^{\wedge} 2 \times \mathrm{R} \times \mathrm{L}$.

The three factors having impact on loss are:

1. Current flowing through network.

2. Resistance of network.

3. Length of network. 
Another factor that has impact on losses is resistance of conductor used for supply of electricity. The resistance is directly proportional to resistivity of material used for design and inversely proportional to square of the cross sectional area. In existing system of LVDS GNAT type of conductor is used for which resistance constant is $1.1566 \mathrm{ohm} / \mathrm{km}$ at 40 degree centigrade. In this technique of conversion of LVDS to HVDS we are changing the type of conductor. In HVDS system WEASEL 0.03 is used for supplying electrical energy for which resistance constant is $0.977 \mathrm{ohm} / \mathrm{km}$ at 40 degree centigrade.

\section{PROPOSED METHODOLOGY}

In this paper $11 \mathrm{KV}$ AGR feeder originating from 33/11 KV Sub Stationis converted in to HVDS as follows,

- Existing LT network on each DTC is reconfigure as High Voltage Distribution network i.e. $11 \mathrm{KV}$ network.

- $\quad 11 \mathrm{kV}$ line is taken as near to the loads as possible.

- LT power supply is fed by providing appropriate capacity transformer and minimum length of LT line.

- It consists of replacement of existing three phase distribution transformer with small capacity transformers.

- Long length LT mains are converted into $11 \mathrm{kV}$ mains by using existing support and thereby installing the appropriate capacity distribution transformer as near as to the load.

For convenience purpose only one DTC i.e. DTC-7 is considered in the paper.

The single line diagram of HVDS network of DTC-7 is shown in below Fig 3. Total 17 No's of farmers are using agricultural pumps for which they are utilizing electricity. Out of 17 No's of farmers 14 No's of farmers are authorized consumers. 3 No's of farmers are connecting illegal hooks to existing LT network and due to implementation of HVDS they are removed as hooking on $11 \mathrm{KV}$ line is not possible.

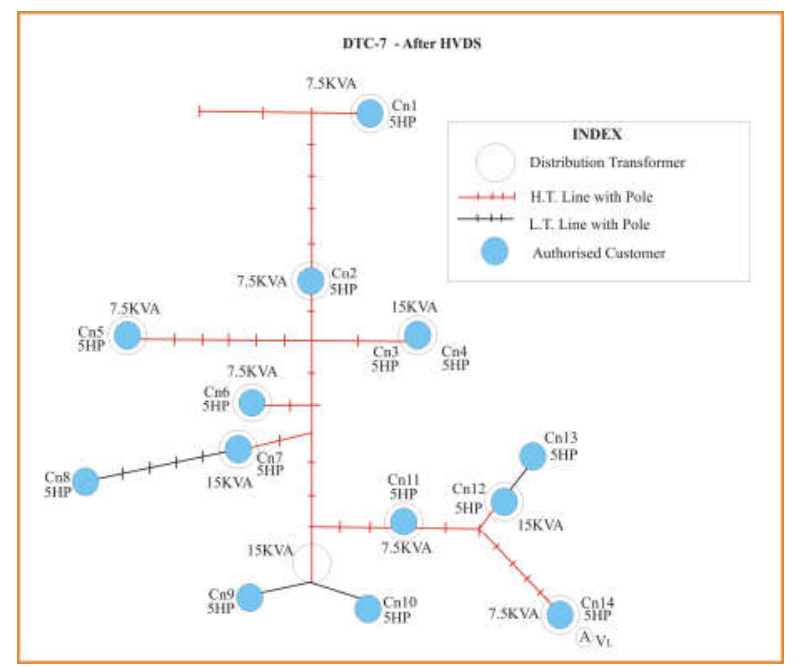

Fig 3 Single line diagram of HVDS network at DTC-7

Existing $100 \mathrm{KVA}$ DTC has been removed and appropriate capacity distribution transformer as near as to the load is placed as shown in Fig 3 and The details of AGR consumers connected at DTC-7 after HVDS is given in Table II
Table II Consumer wise Details of DTC-7 After HVDS

\begin{tabular}{|c|c|c|c|}
\hline \multicolumn{4}{|c|}{ DTC-7 - After HVDS } \\
\hline Sr. No. & $\begin{array}{c}\text { Consumer } \\
\text { Identity }\end{array}$ & LOAD & DTC \\
\hline 1 & $\mathrm{Cn} 1$ & $5 \mathrm{HP}$ & $7.5 \mathrm{KVA}$ \\
\hline 2 & $\mathrm{Cn} 2$ & $5 \mathrm{HP}$ & $7.5 \mathrm{KVA}$ \\
\hline 3 & $\mathrm{Cn} 3$ & $5 \mathrm{HP}$ & \\
\hline 4 & $\mathrm{Cn} 4$ & $5 \mathrm{HP}$ & $15 \mathrm{KVA}$ \\
\hline 5 & $\mathrm{Cn} 5$ & $5 \mathrm{HP}$ & $7.5 \mathrm{KVA}$ \\
\hline 6 & Cn6 & $5 \mathrm{HP}$ & $7.5 \mathrm{KVA}$ \\
\hline 7 & $\mathrm{Cn} 7$ & $5 \mathrm{HP}$ & \\
\hline 8 & $\mathrm{Cn} 8$ & $5 \mathrm{HP}$ & $15 \mathrm{KVA}$ \\
\hline 9 & $\mathrm{Cn} 9$ & $5 \mathrm{HP}$ & \\
\hline 10 & $\mathrm{Cn} 10$ & $5 \mathrm{HP}$ & $15 \mathrm{KVA}$ \\
\hline 11 & Cn11 & $5 \mathrm{HP}$ & $7.5 \mathrm{KVA}$ \\
\hline 12 & $\mathrm{Cn} 12$ & $5 \mathrm{HP}$ & \\
\hline 13 & $\mathrm{Cn} 13$ & $5 \mathrm{HP}$ & $15 \mathrm{KVA}$ \\
\hline 14 & $\mathrm{Cn} 14$ & $5 \mathrm{HP}$ & $7.5 \mathrm{KVA}$ \\
\hline
\end{tabular}

\section{Advantages of HVDS}

- LV system losses can be minimized to the lowest level.

- Pilferage can be minimized by introducing this system.

- Comparative analysis of reconfiguration of existing LV distribution system with HVDS concepts.

- The registered customers will feel ownership and take responsibility.

- Failure will be minimal because of no over loading and no middling of LT lines.

- In the event of equipment failure only limited number of customers will get affected instead of maximum customers in original system.

- Customer has sense of ownership.

- Prevention of unauthorized loads is more effective.

- Considerable reduction in the line losses are there and consequent there is savings in power purchase cost.

- No additional generation capacity is needed for giving new loads due to reduction in power drawls.

- Since the losses are reduced considerably, power can be supplied to additional loads without any further investment of infrastructure.

- Low ratings KVA Distribution Transformers are enough to supply loads.

- Voltage profiles at the loads will be improved, as the DTR's are near to the load centers.

- As High Voltage is transferred near to the loads, the power loss will be less.

- Agricultural Motor burnouts will be eliminated because of good Voltage profiles.

- Reliability of the system can be increased.

- High quality of power supply earns total consumer satisfaction.

\section{SIMULATION ANALYSIS AND RESULT}

The simulation model of $11 \mathrm{KV}$ AGR feeder and all DTCs connected is carried out on both LVDS and HVDS network. The V-I measurement block is showing the measurement of active and reactive power supplied from this feeder to DTC and from DTC to agricultural load. The pole to pole distance 
(span) is 70 meter for HT line and 60 meter for LT line. The HT and LT line is represented by resistive load in simulation analysis. The agricultural pump sets are represented by resistive and inductive load. The transformers are represented by source of power supply.

From simulation recorded power export from substation is noted down and similarly the recorded at consumer's meter is also noted down. In LVDS the loss is calculated directly by difference of these two readings. Same procedure is followed for HVDS and loss is calculated. If we compare loss in both systems we see the huge reduction in losses in HVDS.

Here we are doing analysis of voltage profile also. The circuits in LVDS are lengthy due to this \% VR is very poor at far end of consumer. The LT line spans are limited up to maximum of 5 No's in HVDS system due to this length of circuit is reduced. Hence the \% VR is improved in HVDS.

In order to remove the higher losses observed in low voltage distribution system (LVDS) we are implementing HVDS for the same location and compare the losses. In high voltage distribution system the conductor used in LVDS is replaced by conductor used for high voltage distribution system. In LVDS conductor used for conducting electrical energy is GNAT type of conductor. The conductor constant i.e. resistance $(\mathrm{ohm}) / \mathrm{km}$ of line of GNAT type of conductor is 1.1566 at 40 degree centigrade as per conductor specifications based on I.S. 398/1961. The conductor used in HVDS is Weasel 0.03 type of conductor. The conductor constant i.e. resistance $(\mathrm{ohm}) / \mathrm{km}$ of line of Weasel 0.03 type of conductor is 0.977 at 40 degree centigrade as per conductor specifications based on I.S. 398/1961. Also one of the major change in HVDS is high capacity transformers are also replaced by low capacity transformers due to which high lengthy LT circuits are converted into short length circuits.

In the simulation model of HVDS for $11 \mathrm{KV}$ AGR feeder is emerging out from 33/11 KV substation. We have considered 8 No's. of agricultural DTC for simulation. For convenience purpose only one DTC i.e. DTC-7 is considered in the paper.

Comparison of results of DTC-7 in LVDS \& HVDS is shown in Table III

Table III Comparison of Results of DTC-7 in LVDS \& HVDS

\begin{tabular}{|c|c|c|c|c|}
\hline \multicolumn{5}{|c|}{ DTC-7 Comparison in LVDS \& HVDS } \\
\hline Sr. No. & $\begin{array}{l}\text { Consumer } \\
\text { identity }\end{array}$ & Load & $\begin{array}{c}\text { Power measure } \\
\text { LVDS (w) }\end{array}$ & $\begin{array}{l}\text { Power measured } \\
\text { in HVDS (w) }\end{array}$ \\
\hline 1 & $\mathrm{Cn} 1$ & $5 \mathrm{HP}$ & 3092 & 3327 \\
\hline 2 & $\mathrm{Cn} 2$ & $5 \mathrm{HP}$ & 2567 & 3326 \\
\hline 3 & $\mathrm{Cn} 3$ & $5 \mathrm{HP}$ & 2365 & 3326 \\
\hline 4 & $\mathrm{Cn} 4$ & $5 \mathrm{HP}$ & 2365 & 3326 \\
\hline 5 & $\mathrm{Cn} 5$ & $5 \mathrm{HP}$ & 2340 & 3326 \\
\hline 6 & Cn6 & $5 \mathrm{HP}$ & 2256 & 3321 \\
\hline 7 & $\mathrm{Cn} 7$ & $5 \mathrm{HP}$ & 2192 & 3323 \\
\hline 8 & $\mathrm{Cn} 8$ & $5 \mathrm{HP}$ & 2163 & 3279 \\
\hline 9 & $\mathrm{Cn} 9$ & $5 \mathrm{HP}$ & 2081 & 3313 \\
\hline 10 & $\mathrm{Cn} 10$ & $5 \mathrm{HP}$ & 2081 & 3313 \\
\hline 11 & Cn11 & $5 \mathrm{HP}$ & 2016 & 3321 \\
\hline 12 & $\mathrm{Cn} 12$ & $5 \mathrm{HP}$ & 1963 & 3321 \\
\hline 13 & $\mathrm{Cn} 13$ & $5 \mathrm{HP}$ & 1958 & 3312 \\
\hline 14 & Cn14 & $5 \mathrm{HP}$ & 1932 & 3321 \\
\hline \multicolumn{3}{|c|}{ Total } & 31371 & 46455 \\
\hline
\end{tabular}

Loss calculation of DTC-7 is shown in Table IV. In case of LVDS, the power delivered from DTC is $49550 \mathrm{~W}$ and summation of power recorded at all consumer's meter connected on that DTC is $31371 \mathrm{~W}$. The difference between the two powers is loss in LVDS. The power loss is $18179 \mathrm{~W}$, which is technical loss due to resistance of lines.

Table IVLoss Comparison of DTC-7 in LVDS \& HVDS

\begin{tabular}{ccc}
\hline & LVDS & HVDS \\
\hline Consumption at DTC-7 Point & 49550 & 46840 \\
Total consumption of consumers & 31371 & 46455 \\
Loss in (W) & 18179 & 385 \\
\% Loss & 36.68 & 0.82 \\
\hline
\end{tabular}

Table V Voltage Improvement at Far End Consumer of DTC-7

\begin{tabular}{cccc}
\hline \multicolumn{2}{c}{ Voltage at consumer having identity Cn14 i.e. } & LVDS & HVDS \\
\cline { 2 - 3 } at point A which is far end consumer of the & 316.7 & 415.1 \\
& circuit. & Volts & Volts \\
\cline { 2 - 3 } & $\mathrm{m}$
\end{tabular}

LVDS to HVDS of consumer of DTC-7 having identity as Cn14 i.e. at point A which is the far end consumers of circuit of DTC-7.

Finally, the distribution loss is calculated in existing LVDS system. To calculate the loss we requires readings of meter installed at substation, meters installed at DTC and meters installed at consumer's premises. The substation meter records total power output supplied to AGR load through DTCs. The DTC meters records the sum of total power consumed by legal and illegal consumers. The meters installed at legal consumers premises records the units billed for the registered consumers.

Following three types of losses have been calculated in LVDS as well HVDS system:

- $\quad 11 \mathrm{KV}$ Loss (HT Loss)

- LT Loss

- $11 \mathrm{KV}$ Loss + LT Loss (Total System Loss)

Table VI shows the loss analysis in existing LVDS.

Table VI Analysis of Loss in LVDS

\begin{tabular}{|c|c|c|c|}
\hline Sr. No. & Description & $\begin{array}{c}\text { Power } \\
\text { Measured at } \\
\text { DTC }(W)\end{array}$ & $\begin{array}{c}\text { Summation of } \\
\text { Power Measured a } \\
\text { Consumer end }(W)\end{array}$ \\
\hline 1 & DTC-1 & 34540 & 23150 \\
\hline 2 & DTC-2 & 47010 & 33980 \\
\hline 3 & DTC-3 & 39930 & 25790 \\
\hline 4 & DTC-4 & 34440 & 23160 \\
\hline 5 & DTC-5 & 56220 & 37560 \\
\hline 6 & DTC-6 & 46680 & 32550 \\
\hline 7 & DTC-7 & 49550 & 31370 \\
\hline 8 & DTC-8 & 51980 & 38650 \\
\hline 9 & $\begin{array}{l}\text { Summation of Power } \\
\text { Measured ( } 1 \text { to } 8)\end{array}$ & 360350 & 246210 \\
\hline 10 & $\begin{array}{c}\text { Power measured at feeder at } \\
\text { Substation }\end{array}$ & 363900 & 363900 \\
\hline 11 & Difference $(10-9)$ & 3550 & 117690 \\
\hline \multirow[t]{2}{*}{12} & $\%$ Loss & $\underset{\wedge}{0.97 \%}$ & $\underset{\wedge}{32.34 \%}$ \\
\hline & & HT Loss & System Loss \\
\hline
\end{tabular}

Result i.e. distribution loss is calculated in HVDS system. The details of meter readings are shown in Table VII. To calculate the loss we requires readings of meter installed at substation, meters installed at DTC point and meters installed at consumer's premises. The substation meter records total power output supplied to AGR load through DTCs. The meters at DTC point records the sum of total power consumed by consumers. The meters installed at consumers premises records the units billed for consumers. 
Table VII Analysis of Loss in HVDS

\begin{tabular}{|c|c|c|c|}
\hline Sr. No. & Description & $\begin{array}{c}\text { Power Measured at } \\
\text { DTC }(W)\end{array}$ & $\begin{array}{c}\text { Summation of Power } \\
\text { Measured at } \\
\text { Consumer end (W) } \\
\end{array}$ \\
\hline 1 & DTC-1 & 26850 & 26640 \\
\hline 2 & DTC-2 & 36680 & 36370 \\
\hline 3 & DTC-3 & 29700 & 29490 \\
\hline 4 & DTC-4 & 26490 & 26250 \\
\hline 5 & DTC-5 & 43420 & 42990 \\
\hline 6 & DTC-6 & 40250 & 39910 \\
\hline 7 & DTC-7 & 46840 & 46450 \\
\hline 8 & DTC-8 & 44770 & 44390 \\
\hline 9 & $\begin{array}{l}\text { Summation of Power } \\
\text { Measured (1 to } 8 \text { ) }\end{array}$ & 295000 & 292490 \\
\hline 10 & $\begin{array}{l}\text { Power measured at } \\
\text { feeder at Substation }\end{array}$ & 295800 & 295800 \\
\hline 11 & Difference $(10-9)$ & 800 & 3310 \\
\hline \multirow[t]{2}{*}{12} & \% Loss & $\underset{\wedge}{0.27 \%}$ & $\underset{\wedge}{1.12} \%$ \\
\hline & & HT Loss & System Loss \\
\hline
\end{tabular}

As we see from Table VI and Table VII, distribution system loss is reduced from $32.34 \%$ in LVDS to $1.12 \%$ in HVDS.

\section{Financial Impact \& Payback Period}

From Table VI and Table VII we can find out total power saved in W. From this we can calculate energy saved in terms of money and payback period can be calculated. The difference of power loss in LVDS and power loss in HVDS is the savings of power by implementing this project. It is $114380 \mathrm{~W}$. The electrical supply is fed for agricultural feeder is for only 8 hours a day. The load factor for agricultural load is 0.5 . Hence electrical energy saved in one day is 114.38 $(\mathrm{KW}) * 4$ (hours) $=457.52(\mathrm{KWH})$. From that total money saved in one year is calculated and payback period is calculated from total capital investment and total energy saved in terms of Rupees. Item wise abstract of the funds required for implementation of this project is shown in. Here we can see total $15.84 \mathrm{KM}$ HT line is required to be erected and 53 No's. of small capacity distribution transformers are required to be erected. Total cost necessary for implementation of this project is 102.43 Lakhs.

Table VIII Capex Required ToImplement the HVDS

\begin{tabular}{cccc}
\hline \multicolumn{4}{c}{ Total Infrastructure required } \\
\hline Particulars & Qty. & $\begin{array}{c}\text { Cost/ Item } \\
\text { (Rs.) }\end{array}$ & $\begin{array}{c}\text { Total Cost } \\
\text { (Rs.) }\end{array}$ \\
\hline HT Line (KM) & $15.84 \mathrm{KM}$ & 136456 & 2161463 \\
DT-7.5 KVA & $27 \mathrm{Nos}$ & 148910 & 4020570 \\
DT-10 KVA & $1 \mathrm{No}$ & 151413 & 151413 \\
DT-15 KVA & $19 \mathrm{Nos}$ & 154235 & 2930465 \\
DT-20 KVA & $2 \mathrm{Nos}$ & 158117 & 316234 \\
DT-25 KVA & $3 \mathrm{Nos}$ & 164206 & 492618 \\
DT-30 KVA & $1 \mathrm{No}$ & 169908 & 169908 \\
\multicolumn{4}{c}{ Total Capital Required in Rs. } \\
\hline \multicolumn{4}{c}{} \\
\hline
\end{tabular}

Table IX Calculation of Payback Period

\begin{tabular}{cc}
\hline Total Power Saved (KW) (Total loss in LVDS-Total loss in & $\mathbf{1 1 4 . 3 8}$ \\
HVDS) & $\mathbf{}$ \\
\hline Units saved /Day (Supply for AGR feeder is for 8 Hrs. *(LF=0.5)) & 458 \\
Total units saved in a Year & 167170 \\
Cost of Unit (Rs./KWH) & 6.5 \\
Total Rs. Saved In One Year & 1086605 \\
Total Capex required for HVDS (Rs.) & 10242671 \\
Pay Back Period ( Years ) & 9.4 \\
\hline
\end{tabular}

From above discussion, it seems that, by implementation of HVDS to existing LVDS system, we can reduce the loss from $32.34 \%$ to $1.12 \%$. While achieving this one has to modify the existing LVDS into HVDS by restructuring the network.
For this purpose $15.84 \mathrm{KM}$ of LT line is converted into HT line by utilizing same poles of LT line. Existing high voltage Distribution Transformers are replaced by small capacity Distribution Transformers. In this dissertation, 8 No's of high capacity Distribution Transformers are replaced by 53 No's of small capacity Distribution Transformers. Total cost of restructured infrastructure is $1,02,42,671 /$-.

Hence from, It seems that, by implementation of HVDS we have saved 458 units per day. Accordingly total units saved in one year will be 167170 . Average cost of sale of power is Rs. 6.5 per unit. Hence total saving in one year Will be Rs. $10,86,605 /-$. Hence payback period is calculated 9.4 years.

\section{CONCLUSION}

It is shown that the substantial amount of generated power is being wasted as losses. Therefore, loss minimization in power system has assumed greater significance. HVDS scheme has led to the formulation of new strategy of energy conservation and minimization of transmission and distribution losses by reducing the power theft. In this dissertation, it is concluded that with the adoption of high voltage for distribution i.e. HVDS both the technical as well as non-technical losses are reduced. Effective implementation of HVDS scheme has reduced the failure of transformers. It is concluded that the use of distribution transformer of small rating for two or three consumers has reduced the outages, transformer and power losses due to low current and pilferage to a great extent. Firstly as in HVDS, the registered customers find ownership and take responsibility and not allow others to meddle with the LT Network and even prevents unauthorized loads by the consumers themselves since the distribution transformer may fail if loaded beyond its capacity which reduces the failure rate because of no over loading and no meddling of LT Lines and failure if occur affects only two or three customers instead of 25 to 30 customers in original system. Secondly, the use of high voltage for distribution in HVDS resulted in reduction in losses and improved quality of supply as it is a LT less or less LT system and thus there is practically less voltage drop in LT side and consequent savings in power purchase cost. It also improved the voltage profile and there will be less burnout of motors because of good voltage and less fluctuation. Last but not least it provides better accountability at all level and effective solution to consumer's enquiry and also results in accurate and reliable energy accounts on sustainable basis. Even though there is a drawback of high initial investment, payback period is very less.

\section{References}

1. N.Thirupataiah and N.Saikrishnaprasad, "Minimization Of Distribution Losses By Implementing High Voltage Distribution System In Real Time Applications", International Journal of Emerging Trends In Engineering Research (IJETER), Vol. 3 NO.6, PAGES: 453 - 460 (2015

2. Ritula Thakur and Puneet Chawla, "High voltage distribution system (hvds)-an alternate for improvement of voltage drop", profile international Journal of Engineering Technology, Management and Applied Sciences, January 2015, volume 3 issue 1.

3. Dembra, Amit, and A. K. Sharma. "High voltage Distribution System For Agricultural Feeders In 
Distribution System." International Journal of Engineering Research and Reviews ISSN (2014): 1-8.

4. Spandana, K., 1. Nikhita, and r. A. Varsha. "High Voltage Distribution Systems-For Better Voltage Profile." Proceedings of International Academic Conference on Electrical, Electronics and Computer Engineering (iraj journal). 2013.
5. Gurpreet Kour and R. K. Sharma, "Different Techniques of Loss Minimization in Distribution System", International Journal of Enhanced Research In Science technology \& engineering vol. 2 issue 2, feb.-2013.

\section{How to cite this article:}

Kirankumar P. Shinde and S. R. Deore (2017) ' At\&C Loss Reduction In Electrical Distribution System By Implementation Of HVDS', International Journal of Current Advanced Research, 06(05), pp. 3842-3847.

DOI: http://dx.doi.org/10.24327/ijcar.2017.3847.0379 